\title{
Molecular biology for general readers
}

\author{
Popular books on DNA are replicating quickly, but there is a case for taking seriously a distinctive (and Russian) \\ view of what makes this molecule more interesting than others.
}

PEOPLE should not review books by their close friends, and especially not books by particularly close friends. There are two hazards. First, one may offend the friend, perhaps by offering gratuitous criticism of some element of the book of which he or she is particularly proud, but otherwise (and almost inevitably) by overlooking some such. The second and more serious is that readers in the know will write off the review as a "puff" and promptly think the worse of its author and even of the journal in which the review appears. All that is intended to disarm both categories of potential critics of what follows.

The book concerned is also referred to briefly elsewhere in this issue (see page 330), where David Lilley says he "found it quite hard to put down", but volunteers little else about it except that he "couldn't seriously recommend it to university students". The author is Maxime Frank-Kamenetskii, until last October a member of the faculty of the Russian Academy's Institute of Molecular Genetics in Moscow, but now translated to Boston University. The book is a slim volume called Unraveling DNA and published by VCH Publishers.

A few words of explanation may be helpful. Frank-Kamenetskii is a physicist by origin and thus representative of the Russian school of molecular biologists whose first knowledge of biology may have been culled from Schrödinger's What is Life? It is not in the least surprising that so much of Russian molecular biology has origins such as these. Indeed, the Institute of Molecular Genetics is the outgrowth of a unit set up within the Kurchatov Institute (responsible for reactor design, among other things) by an enlightened director alarmed at Lysenko's influence.

An earlier version of the book appeared in Moscow nearly a decade ago under the title The Most Important Molecule, and was apparently a great success. There are heroic tales of how the English translation was produced in several consecutive all-night sessions in the kitchen of the translator, Lev Liapin, whose wife, Lydia Shepilova, used to manage the production of Scientific American in Moscow. The intended readership is the man or woman in the street.

As such, the book is distinctive because it tells the remarkable (and brief) history of molecular biology as the succession of fits and starts that we all recognize in retrospect. It is indeed the case that there was a minor exodus from molecular biology in the $1960 \mathrm{~s}$ when, with the mechanisms of replication NATURE · VOL 367 - 27 JANUARY 1994 (of DNA) and translation (of DNA into RNA) sketched out, and with the essence of the genetic code established, some thought the time had come to pay attention to other problems, the nervous system perhaps.

Then, within a year or so, there was reverse transcriptase (for turning RNA into DNA), which Frank-Kamenetskii says was less remarkable for its ideological significance than as a tool for the genetic engineers who quickly trooped along, stitching stretches of complementary (to RNA) DNA, now cDNA, into bacterial plasmids to manufacture the corresponding proteins. Since then, of course, there has hardly been a pause.

With all that said, this is a physicist's tale not only because it documents the antecedents of molecular biology in physics (Astbury, Bragg, Delbruck, Schrödinger and the like) but also because it abounds with illustrations of the kind physics teachers are forever using with their classes. The helical coil of DNA in a single human cell would be two metres long if fully stretched, right? But that is a factor of $10^{6}$ greater than the dimensions of a cell nucleus, in which all the DNA is packed.

So can the compactness of the chromosomes be explained by random packing of the DNA, as in a ball of tangled wool? Sadly, a random walk calculation (made accessible by a tale of a man lost in a wood) shows that only a factor of 1,000 can be recovered that way. So there must be devices such as supercoiling, not to mention nucleosomes (made of histone protein) on which these coiled structures are wound.

Frank-Kamenetskii's other compelling rhetorical technique is to pretend for the benefit of readers that readers are intelligent beings. Take, for example, the difference between the genetic code that holds sway in the nucleus of a cell and that common to mitochondria. If mitochondria are indeed the relics of primitive prokaryotes that once formed symbiotic relationships with others to form now recognizable organisms, would one not expect the mitochondrial version of the genetic code to be the primordial version?

One would indeed, but one would be mistaken. Simple logic dictates that. With the transfer of some mitochondrial genes to the nucleus after the original symbiosis, it is just as likely that the mitochondrial code may have freed afterwards to evolve by the modest amount required to account for the observed difference. The interest of this technique is that its draws even general readers into current controversies, leaving them not with a flat statement that some question is still decided, but with a vivid curiosity about the outcome.

Frank-Kamenetskii's own chief interest is in the structure of DNA. Sometimes, in conversation, he gives the impression that if only people were to think more carefully about the implications of what is known of the structure of DNA for the behaviour of the molecule in real life, much that is at present obscure would be understood. That interest no doubt explains the account of the role of supercoiling in the functioning of circular DNA molecules. Mathematicians (particularly topologists) are given full credit, as is James Wang of Harvard, the pioneer of the idea that topological invariants have a place in molecular biology.

The point of all this, in a book for general readers, is straightforward. Inevitably it is tempting, in describing progress in this field, to create the impression that everything has been so successful that there are hardly any problems left. But the truth may often be quite the opposite; the more successful and the more quickly moving some series of studies may have been, the more loose ends will probably have been left untied. But supercoiling is at least a way of accounting for the prevalence of the weird elements of nucleic acid structure such as the hairpins and the cruciform structures known to be prevalent in RNA molecules and likely, Frank-Kamenetskii guesses, in DNA structures as well.

As popular books on DNA do, this one ends (perhaps too suddenly) with an account of how molecular biology may be exploited for useful purposes in the years ahead - understanding cancer and perhaps curing (by gene therapy) some forms of it, and so on. But it is a proper question to ask whether, at the end of an essay in which readers have been half-persuaded that they too could be armchair molecular biologists by taking sufficient thought, that is the best place to leave them.

Much earlier, Frank-Kamenetskii has a chapter called "Where do genes come from?" which rehearses some of the questions commonly raised about the origin of life, but which is mostly an opportunity to explain that many genes have apparently meaningless introns scattered through their length, and that the genes of the immune system's ingredients are capable of rearrangement. But in reality, the most arresting question for the man or woman in the street is that of how life itself began. What molecular biology has done is to make even that question accessible.

John Maddox 